\title{
$C$ reactive protein levels are increased in non-allergic but not allergic asthma: a multicentre epidemiological study
}

\author{
I S Ólafsdottir, T Gislason, B Thjodleifsson, Í Olafsson, D Gislason, R Jögi, C Janson
}

Thorax 2005;60:451-454. doi: 10.1136/thx.2004.035774

See end of article for authors' affiliations

.....................

Correspondence to:

Professor T Gislason,

Department of Allergy,

Respiratory Medicine and

Sleep, Landspitali

University Hospital, 108

Reykjavík, Iceland;

thorarig@landspitali.is

Received 19 October 2004

Accepted

10 February 2005

\begin{abstract}
Background: High sensitivity $\mathrm{C}$ reactive protein $\left(\mathrm{H}_{\mathrm{s}} \mathrm{CRP}\right)$ is an inflammatory marker known to be related to smoking, obesity, and cardiovascular disease. A study was undertaken to determine whether $\mathrm{HsCRP}_{\mathrm{s}}$ related to respiratory symptoms, asthma, atopy, and bronchial hyperresponsiveness in population samples from three countries.

Methods: HsCRP was measured in 1289 subjects from three centres in ECRHS II: Reykjavik, Uppsala and Tartu. The HsCRP values ranged from $<0.01 \mathrm{mg} / \mathrm{l}$ to $70.0 \mathrm{mg} / \mathrm{l}$ and were divided into four equal groups $(\leqslant 0.45,0.46-0.96,0.97-2.21$, and $>2.21 \mathrm{mg} / \mathrm{l})$.

Results: $\mathrm{HsCRP}_{\mathrm{s}}$ increased with increasing body mass index $(r=0.41 ; p<0.0001)$ and was higher in smokers than in never smokers $(p=0.02)$. A significant relationship was found between increased HsCRP levels and respiratory symptoms such as wheeze, attacks of breathlessness after effort, and nocturnal cough $(\mathrm{p}<0.0001)$. The crude odds ratio $(95 \% \mathrm{Cl})$ for the probability of non-allergic asthma was 3.57 (1.83 to 6.96) for subjects in the 4 th quartile compared with the 1 st quartile of HsCRP. This association remained significant after adjusting for study centre, age, sex, body weight, and smoking history (OR 2.19 $(95 \% \mathrm{Cl} 1.04$ to 4.63$))$. No significant relationship was observed between $\mathrm{HsCRP}$ and allergic asthma or bronchial responsiveness.

Conclusions: Raised levels of $\mathrm{H}_{\mathrm{S}} \mathrm{CRP}$ are significantly associated with respiratory symptoms and nonallergic asthma but not with allergic asthma.
\end{abstract}

reactive protein (CRP) is a highly sensitive marker of inflammation, infection, and tissue damage which contributes to host defence against infection by activating the complement pathways. ${ }^{1}$ The rise in CRP is driven by its rate of synthesis and falls rapidly when the pathological stimulus ceases with a plasma half life of approximately 19 hours. ${ }^{12}$ Highly sensitive assays for CRP (HsCRP) are available and reflect low grade inflammation. ${ }^{3}$ CRP is produced by hepatocytes under transcriptional control by the proinflammatory cytokine interleukin (IL)-6, but adipose tissue has an active role in its metabolism by producing about $30 \%$ of IL-6. ${ }^{1}{ }^{4} 5$

A positive relationship has been reported between raised CRP levels and current asthma, ${ }^{67}$ respiratory impairment, ${ }^{8-11}$ and bronchial hyperresponsiveness. ${ }^{12}$ The association between asthma and CRP is by no means clear, however, and could at least in part reflect the role of obesity in CRP production $^{45}$ as asthma in young adults is significantly more common in subjects with a raised body mass index (BMI)..$^{13-15}$ Whether there is a difference in the association between HsCRP and atopic and non-atopic asthma is unknown.

The aim of this paper was to explore the relationship between HsCRP, respiratory symptoms, bronchial responsiveness, asthma, and atopy in a randomly selected group of young adults in Reykjavik, Uppsala, and Tartu.

\section{METHODS}

Population

The European Community Respiratory Health Survey (ECRHS) is an international multicentre study of asthma and allergy. The first part, ECRHS I, was conducted in 1990-4 and the follow up study, ECRHS II, in 1999-2001. The design of ECRHS I and ECRHS II has been published in detail. ${ }^{16}{ }^{17}$ Each participant was sent a brief questionnaire (stage 1) and, from those who responded, a random sample was invited to undergo a more detailed clinical examination (stage 2). In addition, a "symptomatic sample" consisting of those who reported symptoms of waking with shortness of breath, asthma attacks, or using asthma medication in stage 1 was also studied. In ECRHS II subjects who had participated in stage 2 of ECRHS I were invited to participate in a follow up study (www.ECRHS.org). Subjects answered a standardised questionnaire administered by trained interviewers and underwent lung function and blood tests. The present study includes data from three of the 29 centres in the ECRHS IIReykjavik in Iceland, Tartu in Estonia, and Uppsala in Sweden-where 2033 subjects participated in stage 2 of ECRHS I. The number of subjects in the present analysis was 1289, of which 512 were from Reykjavik, 288 from Tartu and 489 from Uppsala (participation rate 63.4\%).

Subjects were asked to postpone their examination if they had suffered from respiratory infection in the 3 weeks immediately preceding the examination as this was a criterion for exclusion. Written informed consent was obtained from each subject before inclusion in the study. The protocol was approved by the National Bioethics Committee of Iceland, the ethics committee of the Medical Faculty, Uppsala University, and the ethics review committee on human reseach of the University of Tartu.

\section{Respiratory symptoms and asthma}

The subjects underwent a structured interview which included detailed information on respiratory symptoms and asthma. The symptoms included in this analysis had all occurred during the preceding 12 months and were wheeze; wheeze in combination with breathlessness; wheeze when not having a cold; nocturnal chest tightness; attacks of breathlessness following activity, at rest or at night time; and nocturnal cough. "Asthma" was defined as having physician

Abbreviations: $B M I$, body mass index; $C R P, C$ reactive protein; $\mathrm{H}_{s} C R P$, high sensitivity $C$ reactive protein 
diagnosed asthma and having had asthma related symptoms or attacks of asthma in the preceding 12 months. ${ }^{16}$

\section{Allergy testing}

Total and specific serum IgE was determined using the Pharmacia CAP System (Pharmacia Diagnostics, Uppsala, Sweden). In all centres specific IgE was measured against Dermatophagoides pteronyssinus, timothy grass, cat, and Cladosporium herbarum. Detection of specific IgE $(\geqslant 0.35 \mathrm{kU} /$ l) was used as the definition of sensitisation. Atopy was defined as being sensitised to any of the above allergens.

In this analysis allergic asthma was defined as having asthma in combination with atopy, while non-allergic asthma was defined as having asthma but not having atopy.

\section{Body mass index}

BMI was calculated as weight in kilograms divided by the square of height in metres.

\section{Bronchial responsiveness}

Methacholine challenge was carried out using a dosimeter (Mefar, Brescia, Italy) in all subjects with none of the exclusion criteria defined in the international ECRHS protocol (www.ECRHS.org) and described in detail in a recent publication. ${ }^{17}$ The level of bronchial responsiveness was expressed using a dose-response slope. ${ }^{17}$

\section{Smoking}

Information on smoking history was collected by administering a questionnaire on each occasion. For those who answered "yes" to the lead question ("Have you ever smoked for as long as a year?"), additional questions were asked on age at starting, amount smoked currently, whether they had stopped or cut down, and amount smoked previously. Based on this information, the subjects were classified into "never smokers", "ex-smokers" (before ECRHS I), "quitters" (between ECRHS I and II), "starters" (between ECRHS I and II), and "smokers".

\section{HsCRP measurements}

All laboratory measurements were carried out at the Department of Clinical Biochemistry, Landspitali University Hospital, Iceland. Serum samples were stored frozen at $-20^{\circ} \mathrm{C}$. HsCRP concentrations were measured on a Hitachi 911 analyser using a commercially available latex enhanced immunoturbidimetric assay from Roche. The lower detection limit of the assay is $0.1 \mathrm{mg} / \mathrm{l}$. The between-day coefficient of variation was $1.1 \%$ at a concentration of $3.73 \mathrm{mg} / \mathrm{l}$ and $1.9 \%$ at a concentration of $0.68 \mathrm{mg} / \mathrm{l}$.

\section{Statistical analyses}

All statistics were calculated with STATA software, version intercooled STATA 8.0 for Windows. Log-transformed values of HsCRP were used when comparing means between groups and in regression models. One way analysis of variation was used to compare HsCRP levels in non-asthmatics, allergic, and non-allergic asthmatics. The subjects were divided into four groups according to the quartile distribution of the HsCRP values ( $\leqslant 0.45,0.46-0.96,0.97-2.21$ and $>2.21 \mathrm{mg} / \mathrm{l})$ when estimating risk association. Odds ratios were calculated using logistic regression. The adjusted risk ratios and 95\% confidence interval (CI) were first analysed on pooled data from all three centres, adjusting for centre, and then calculated separately at each centre. Potential heterogeneity between centres was examined using standard methods for random effects meta-analysis. ${ }^{18}$

\section{RESULTS}

The general characteristics of non-asthmatic $(n=1100)$ and asthmatic participants $(\mathrm{n}=189)$ are summarised in table 1 . The non-allergic asthmatic subjects were more often women and they also reported smoking more often than the asthmatic participants.

The HsCRP values ranged from $<0.1 \mathrm{mg} / \mathrm{l}$ to $70.0 \mathrm{mg} / \mathrm{l}$. The distribution was skewed but normally distributed after log transformation. There were no significant centre or sex differences in HsCRP levels, but there was a weak but statistically significant positive correlation between age and HsCRP $(r=0.10 ; \mathrm{p}=0.0003)$. HsCRP increased with increasing BMI ( $p<0.0001$, fig 1$)$ and was higher in current smokers than in never smokers (geometric mean 1.17 (95\% CI 1.02 to 1.33) $v 0.92(95 \%$ CI 0.83 to 1.01$), \mathrm{p}<0.02)$.

\section{HsCRP and respiratory symptoms}

The prevalence of most respiratory symptoms increased with increasing HsCRP (table 2) and there was a significant difference between the quartile with the lowest levels of HsCRP $(\leqslant 0.45)$ and the highest quartile $(>2.21)$ for most of the symptoms.

\section{HsCRP, atopy, and bronchial responsiveness}

A weak positive correlation was found between HsCRP and total IgE $(r=0.07, \mathrm{p}=0.01)$. There was no significant relation between HsCRP and atopy (adjusted OR 0.95 (95\%

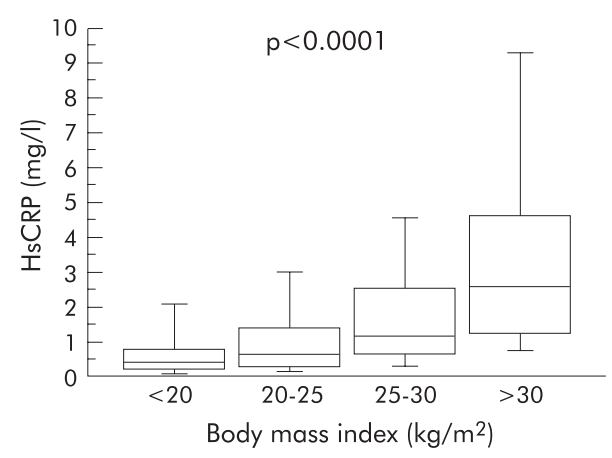

Figure 1 Relationship between $\mathrm{HsCRP}_{\mathrm{s}}$ and body mass index.

Table 1 Respiratory symptoms and atopy in relation to $\mathrm{HsCRP}_{\text {(mean }}$ (SD) and \%)

\begin{tabular}{|c|c|c|c|c|c|}
\hline & $\begin{array}{l}\text { No asthma } \\
(n=1100)\end{array}$ & $\begin{array}{l}\text { Allergic asthma } \\
(n=103)\end{array}$ & $p$ value & $\begin{array}{l}\text { Non-allergic asthma } \\
(n=86)\end{array}$ & $p$ value \\
\hline Age & $41.6(7.2)$ & $40.5(7.3)$ & 0.27 & $43.3(7.4)$ & 0.11 \\
\hline Women & 51.2 & 43.7 & 0.15 & 75.6 & $<0.0001$ \\
\hline Smoking history & & & 0.005 & & 0.52 \\
\hline Never smokers & 42.1 & 56.3 & & 44.2 & \\
\hline Ex-smokers & 30.1 & 29.1 & & 24.4 & \\
\hline Smokers & 27.8 & 14.6 & & 31.4 & \\
\hline $\mathrm{BMI}$ & $25.4(4.1)$ & $26.1(4.7)$ & 0.38 & $26.5(4.7)$ & 0.09 \\
\hline
\end{tabular}


Table 2 Respiratory symptoms and atopy in relation to $\mathrm{H}_{s} \mathrm{CRP}$

\begin{tabular}{|c|c|c|c|c|c|c|c|}
\hline & $\begin{array}{l}\text { 1st quartile } \\
\text { CRP } \\
\leqslant 0.45\end{array}$ & $\begin{array}{l}\text { 2nd quartile } \\
\text { CRP } \\
0.46-0.96\end{array}$ & OR $(95 \% \mathrm{Cl})^{*}$ & $\begin{array}{l}\text { 3rd quartile } \\
\text { CRP } \\
0.97-2.21\end{array}$ & OR $(95 \% \mathrm{Cl})^{*}$ & $\begin{array}{l}\text { 4th quartile } \\
\text { CRP } \\
>2.21\end{array}$ & OR $(95 \% \mathrm{Cl})^{*}$ \\
\hline Wheeze & 17.3 & 23.1 & $1.22(0.81$ to 1.93$)$ & 27.3 & 1.40 (0.93 to 2.12$)$ & 36.0 & 1.93 (1.27 to 2.93 ) \\
\hline Wheeze and breathlessness & 11.3 & 12.2 & $0.98(0.59$ to 1.63$)$ & 14.8 & $1.24(0.75$ to 2.03$)$ & 20.4 & $1.63(0.99$ to 2.03$)$ \\
\hline Wheeze without a cold & 12.2 & 16.0 & $1.21(0.76$ to 1.94$)$ & 19.3 & $1.46(0.92$ to 2.32$)$ & 23.3 & 1.67 (1.04 to 2.69$)$ \\
\hline Nocturnal chest tightness & 12.8 & 10.9 & $0.84(0.51$ to 1.40$)$ & 16.7 & 1.39 (0.86 to 2.24$)$ & 19.2 & 1.53 (0.93 to 2.49$)$ \\
\hline Breathless at rest & 6.4 & 6.4 & $1.15(0.59$ to 2.25$)$ & 9.1 & 1.88 (0.99 to 3.58$)$ & 11.9 & 2.07 (1.08 to 3.94$)$ \\
\hline Breathless after effort & 15.5 & 18.0 & $1.20(0.78$ to 1.86$)$ & 21.4 & $1.41(0.91$ to 2.18$)$ & 30.2 & 2.08 (1.34 to 3.22$)$ \\
\hline Nocturnal breathlessness & 7.9 & 6.2 & $0.94(0.49$ to 1.82$)$ & 9.7 & $1.55(0.84$ to 2.86$)$ & 9.4 & $1.36(0.71$ to 2.60$)$ \\
\hline Nocturnal cough & 18.6 & 26.0 & 1.48 (1.06 to 2.38$)$ & 28.3 & 1.59 (1.06 to 2.38$)$ & 37.3 & 2.11 (1.40 to 2.38$)$ \\
\hline
\end{tabular}

CI 0.62 to 1.44$)$ ) or between HsCRP and bronchial responsiveness $(r=0.02, \mathrm{p}=0.51)$.

\section{HsCRP and asthma}

Asthmatic subjects had higher HsCRP values than nonasthmatic participants (geometric mean 1.35 (95\% CI 1.14 to 1.61) $v 0.96$ (95\% CI $0.90-1.03) \mathrm{mg} / \mathrm{l}, \mathrm{p}=0.0002)$. Subjects with non-allergic asthma had significantly higher levels of HsCRP than non-asthmatic subjects, whereas subjects with allergic asthma had levels similar to non-asthmatic subjects (fig 2).

The association between HsCRP and non-allergic asthma remained significant after adjusting for age, sex, smoking, BMI, and centre (table 3). The relationship between BMI and allergic and non-allergic asthma is shown in table 4. Before adjustment for HsCRP, increasing BMI was associated with both allergic and non-allergic asthma. After adjustment for HsCRP the association between BMI and allergic asthma remained significant while no significant association was found between non-allergic asthma and BMI. No significant interaction was found between BMI and HsCRP in relation to allergic and non-allergic asthma.

\section{Meta-analysis and centre heterogeneity}

The association between HsCRP, respiratory symptoms, and asthma was also assessed by meta-analysis. The estimates were similar to those derived when analysing the pooled data. Significant centre heterogeneity was found for the relationship between HsCRP and wheeze without a cold $(p=0.04)$, attacks of breathlessness following activity $(\mathrm{p}=0.02)$, and breathlessness at rest $(\mathrm{p}=0.04)$, with higher odds ratios in Tartu than at the other two centres. No

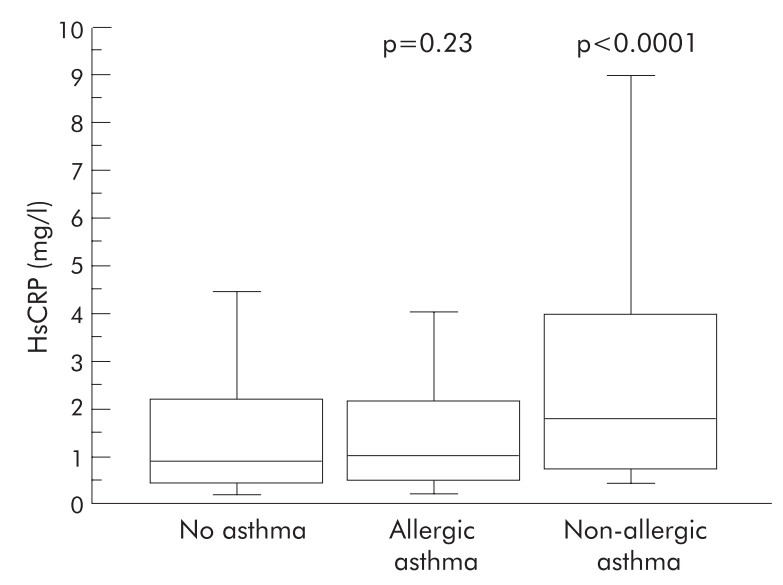

Figure 2 Relationship between $\mathrm{HsCRP}_{\mathrm{s}}$ and no asthma, allergic asthma, and non-allergic asthma ( $p$ values calculated in comparison with nonasthmatic subjects). heterogeneity was found for the association between HsCRP and the other respiratory symptoms or asthma.

\section{DISCUSSION}

Our study confirms previous results which found that HsCRP is related to age, BMI, and smoking. Our novel finding is, however, that non-allergic asthma is strongly related to higher HsCRP levels whereas allergic asthma is not. There was also a strong association between high HsCRP values and respiratory symptoms such as wheeze, breathlessness after effort, and nocturnal cough. This brings into focus the triad: asthma, high BMI, and high HsCRP.

Several studies have recently reported a strong association between increasing asthma prevalence and increasing $\mathrm{BMI},{ }^{15}{ }^{19} 20$ but the causality is unknown. Schachter et $a l^{21}$ reported that obesity (BMI $\geqslant 30$ ) was a risk factor for selfreported asthma and wheeze but this group did not have higher levels of atopy, airway hyperresponsiveness or airway obstruction. Sin $e^{2} a^{22}$ also found that obese subjects reported a higher point prevalence of self-reported asthma, although they had a lower prevalence of significant airflow obstruction.

Many factors are associated with both asthma and obesity which complicates the picture. Firstly, in contradiction to that mentioned earlier in the discussion, obesity might be a consequence of asthma as these subjects have reduced exercise capacity and obesity is a known side effect of oral steroid treatments. Secondly, gastro-oesophageal reflux and obstructive sleep apnoea are both possible risk factors for asthma development and are related to obesity. ${ }^{14}{ }^{23}$ Thirdly, obesity has detrimental effects on respiratory symptoms and lung function, and weight reduction in obese asthmatics has been associated with improvement in symptoms, lung function, and quality of life. ${ }^{24} 25$ In overweight women weight loss has been shown to be independently associated with both improvements in glucose metabolism and decreased CRP. ${ }^{26}$ In our study the association between obesity and CRP levels was equally strong for allergic and non-allergic asthma. In the non-allergic asthma group this association became non-significant when adjusting for HsCRP levels but

Table 3 Odds ratio (95\% confidence interval)* for the relationship between $\mathrm{H}_{\mathrm{s}} \mathrm{CRP}$ (expressed in quartiles and as a continuous variable) and allergic and non-allergic asthma

\begin{tabular}{lll}
\hline HsCRP (mg/l) & Allergic asthma & Non-allergic asthma \\
\hline$<0.45$ & 1 & 1 \\
$0.45-0.96$ & $0.87(0.47$ to 1.61$)$ & $0.76(0.33$ to 1.76$)$ \\
$0.97-2.21$ & $0.89(0.48$ to 1.64$)$ & $1.57(0.73$ to 3.36$)$ \\
$>2.21$ & $0.64(0.32$ to 1.27$)$ & $2.19(1.04$ to 4.63$)$ \\
Log HsCRP & $0.90(0.73$ to 1.12$)$ & $1.46(1.16$ to 1.82$)$ \\
\hline
\end{tabular}

*Adjusted for centre, age, sex, and smoking history. 
Table 4 Odds ratio (95\% confidence interval)* for the relationship between body mass index and $\mathrm{H}_{\mathrm{s}} \mathrm{CRP}$

\begin{tabular}{llllll}
\hline & \multicolumn{2}{l}{ Without adjustment for HsCRP } & & \multicolumn{2}{l}{ With adjustment for HsCRP (quartiles) } \\
\cline { 2 - 3 } \cline { 5 - 6 } Body mass index & Allergic asthma & Non-allergic asthma & & Allergic asthma & Non-allergic asthma \\
\hline$<20 \mathrm{~kg} / \mathrm{m}^{2}$ & $0.95(0.31$ to 2.87$)$ & $1.14(0.37$ to 3.46$)$ & & $0.96(0.32$ to 2.92$)$ & $1.34(0.43$ to 4.20$)$ \\
$20-25 \mathrm{~kg} / \mathrm{m}^{2}$ & 1 & 1 & & $1.32(0.79$ to 2.19$)$ & $1.25(0.62$ to 2.50$)$ \\
$>25-30 \mathrm{~kg} / \mathrm{m}^{2}$ & $1.24(0.76$ to 2.04$)$ & $1.24(0.73$ to 2.12$)$ & & $1.22(1.09$ to 4.51$)$ & $1.34(0.43$ to 4.20$)$ \\
$>30 \mathrm{~kg} / \mathrm{m}^{2}$ & $1.92(0.99$ to 3.71$)$ & $1.89(1.00$ to 3.60$)$ & & $2.22)$ & \\
Per $5 \mathrm{~kg} / \mathrm{m}^{2}$ increase & $1.31(1.03$ to 1.66$)$ & $1.34(1.06$ to 1.71$)$ & & $1.39(1.08$ to 1.81$)$ & $1.13(0.87$ to 1.48$)$ \\
\hline *Adjusted for centre, age, sex, and smoking history. & & &
\end{tabular}

remained significant in the group with allergic asthma. This indicates that the pathophysiological background for the association between asthma and obesity differ between allergic and non-allergic asthma.

Previous studies have shown that patients with allergic and non-allergic asthma differ in many aspects, including responsiveness to cold air, response to adenosine monophosphate (AMP), ${ }^{27}$ levels of nitrogen oxide (NO) in expired air, ${ }^{28}$ and the level of eosinophilic inflammation in the airways. ${ }^{29}$ Our results show an association between increased HsCRP and non-allergic asthma even when adjusted for body weight, but the lack of association between HsCRP and allergic asthma further emphasises the difference between these two subgroups of asthma. The increased HsCRP levels in non-allergic asthma support the theory that, in non-atopic asthma, there is not only a local but also an ongoing systemic inflammatory process.

We conclude that increased levels of HsCRP are significantly associated with respiratory symptoms and non-allergic asthma but not with allergic asthma. Further studies on the possible role of CRP in the pathogenesis of non-allergic asthma could lead to a recognition of new biomarkers, other mechanisms which we have not corrected for, or even new therapeutic possibilities. HsCRP might in the near future be used as a risk factor marker for lung diseases.

\section{ACKNOWLEDGEMENTS}

The authors thank A S Ingvarsdottir and V A Gunnlaugsdottir for their expert technical assistance.

\section{Authors' affiliations}

I S Ólafsdottir, T Gislason, D Gislason, Department of Allergy,

Respiratory Medicine and Sleep, Landspitali University Hospital, 108 Reykjavik, Iceland

B Thiodleifsson, Department of Gastroenterology, Landspitali University Hospital, 101 Reykjavik, Iceland

Í Olafsson, Department of Clinical Biochemistry, Landspitali University Hospital, 108 Reykjavík, Iceland

R Jögi, Lung Clinic, Tartu University Clinics, Estonia

C Janson, Department of Medical Sciences: Respiratory Medince and Allergology, Uppsala University, Sweden

The study was supported financially by the Icelandic Research Council, the Swedish Heart and Lung Foundation, the Vardal Foundation for Health Care Science and Allergy Research, the Swedish Association Against Asthma and Allergy, and the Estonian Science Foundation grant no 4350 .

\section{REFERENCES}

1 Pepys MB, Hirschfield GM. C-reactive protein: a critical update. J Clin Invest 2003;111:1805-12.

2 Vigushin DM, Pepys MB, Hawkins PN. Metabolic and scintigraphic studies of radioiodinated human C-reactive protein in health and disease. J Clin Invest 1993;91:1351-7

3 Wilkins J, Gallimore JR, Moore EG, et al. Rapid automated high sensitivity enzyme immunoassay of C-reactive protein. Clin Chem 1998;44:1358-61.

4 Yudkin JS, Stehouwer CD, Emeis JJ, et al. C-reactive protein in healthy subjects: associations with obesity, insulin resistance, and endothelial dysfunction: a potential role for cytokines originating from adipose tissue? Arterioscler Thromb Vasc Biol 1999;19:972-8.

5 Visser M, Bouter LM, McQuillan GM, et al. Elevated C-reactive protein levels in overweight and obese adults. JAMA 1999;282:2131-5.

6 Ford ES. Asthma, body mass index, and C-reactive protein among US adults. J Asthma 2003;40:733-9.

7 Jousilahti P, Salomaa V, Hakala K, et al. The association of sensitive systemic inflammation markers with bronchial asthma. Ann Allergy Asthma Immunol 2002;89:381-5.

8 Cirillo DJ, Agrawal Y, Cassano PA. Lipids and pulmonary function in the Third National Health and Nutrition Examination Survey. Am J Epidemiol 2002;155:842-8

9 Danesh J, Wheeler JG, Hirschfield GM, et al. C-reactive protein and other circulating markers of inflammation in the prediction of coronary heart disease. N Engl J Med 2004;350:1387-97.

10 Mannino DM, Ford ES, Redd SC. Obstructive and restrictive lung disease and markers of inflammation: data from the Third National Health and Nutrition Examination. Am J Med 2003;1 14:758-62.

11 Gan WQ, Man SFP, Senthilselvan A, et al. Association between chronic obstructive pulmonary disease and systemic inflammation: a systematic review and a meta-analysis. Thorax 2004;59:574-80.

12 Kony S, Zureik M, Driss F, et al. Association of bronchial hyperresponsiveness and lung function with C-reactive protein (CRP): a population based study. Thorax 2004;59:892-6.

13 Jarvis D, Chinn S, Potts J, et al. Association of body mass index with respiratory symptoms and atopy: results from the European Community Respiratory Health Survey. Clin Exp Allergy 2002;32:831-7.

14 Gislason T, Janson C, Vermeire P, et al. Respiratory symptoms and nocturnal gastroesophageal reflux: a population-based study of young adults in three European countries. Chest 2002;121:158-63.

15 Gunnbjornsdottir MI, Omenaas E, Gislason T, et al. Obesity and nocturnal gastro-oesophageal reflux are related to onset of asthma and respiratory symptoms. Eur Respir J 2004;24:116-21.

16 Janson C, Chinn S, Jarvis D, et al. Physician-diagnosed asthma and drug utilization in the European Community Respiratory Health Survey. Eur Respir J 1997; 10:1795-802.

17 Chinn S, Burney P, Jarvis D, et al. Variation in bronchial responsiveness in the European Community Respiratory Health Survey (ECRHS). Eur Respir J 1997; 10:2495-501.

18 DerSimonian R, Laird N. Meta-analysis in clinical trials. Control Clin Trials 1986;7:177-88.

19 Chen $Y$, Dales R, Tang M, et al. Obesity may increase the incidence of asthma in women but not in men: longitudinal observations from the Canadian National Population Health Surveys. Am J Epidemiol 2002;155:191-7.

20 Beckett WS, Jacobs DR Jr, Yu X, et al. Asthma is associated with weight gain in females but not males, independent of physical activity. Am J Respir Crit Care Med 2001;164:2045-50.

21 Schachter LM, Salome CM, Peat JK, et al. Obesity is a risk for asthma and wheeze but not airway hyperresponsiveness. Thorax 2001;56:4-8.

22 Sin DD, Jones RL, Man SF. Obesity is a risk factor for dyspnea but not for airflow obstruction. Arch Intern Med 2002;162:1477-81.

23 Richter JE. Gastroesophageal reflux disease and asthma: the two are directly related. Am J Med 2000;108(Suppl 4a):153-8S.

24 Stenius-Aarniala B, Poussa T, Kvarnstrom J, et al. Immediate and long term effects of weight reduction in obese people with asthma: randomised controlled study. BMJ 2000;320:827-32.

25 Hakala K, Stenius-Aarniala B, Sovijarvi A. Effects of weight loss on peak flow variability, airways obstruction, and lung volumes in obese patients with asthma. Chest 2000;118:1315-21.

26 Ryan AS, Nicklas BJ. Reductions in plasma cytokine levels with weight loss improve insulin sensitivity in overweight and obese postmenopausal women. Diabetes Care 2004;27:1699-705.

27 Ludviksdottir D, Janson C, Bjornsson E, et al. Different airway responsiveness profiles in atopic asthma, nonatopic asthma, and Sjogren's syndrome. BHR Study Group. Bronchial hyperresponsiveness. Allergy 2000;55:259-65.

28 Ludviksdottir D, Janson C, Hogman M, et al. Exhaled nitric oxide and its relationship to airway responsiveness and atopy in asthma. BHR Group. Respir Med 1999;93:552-6.

29 Amin K, Ludviksdottir D, Janson C, et al. Inflammation and structural changes in the airways of patients with atopic and nonatopic asthma. BHR Group. Am J Respir Crit Care Med 2000;162:2295-301. 